Sc Danko Jovanović, pukovnik, dipl. inž. VP 5055, Beograd

\section{IZMEŠTANJE REMONTNIH KAPACITETA}

UDC: $355.753: 355.742]: 355.415 .2$

Rezime:

U radu su definisani elementi sistema održavanja i uslovi pod kojima se vrši njihovo izmeštanje. Objašnjeni su kriterijumi za izbor mesta razmeštaja jedinica za održavanje. Jedinice za održavanje razmatraju se kao borbene jedinice koje moraju zadovoljiti visoku gotovost i rentabilnost $u$ poslovanju.

Ključne reči: kriterijum, remontni kapaciteti, gotovost, rentabilnost.

\title{
DISLOCATION OF OVERHAUL CAPACITIES
}

Summary:

Maintenance system elements are defined as well as the conditions under which their dislocation is performed. The criteria for the choice of location for maintenance unit dislocation are discussed. Maintenance units are treated as combat units which have to maintain a high level of readiness and be cost-effective at the same time.

Key words: criterion, overhaul capacities, readiness, cost-effectiveness.

\section{Uvod}

Jedan od osnovnih preduslova za uspešno izvođenje borbenih dejstava jeste održavanje visokog stepena ispravnosti sredstava ratne tehnike (SRT). Veoma je važno da se stvore uslovi za stalno održavanje SRT u ispravnom stanju, odnosno njihovo brzo dovođenje $u$ ispravno stanje u slučaju neispravnosti ili havarije. Da bi sistem održavanja (SOd) u celini funkcionisao neprekidno i uspešno potrebno je, u određenim uslovima kao što su neposredna ratna opasnost, rat i prirodne katastrofe, sačuvati remontne resurse od uništenja, ili ih staviti u povoljniji položaj, kako bi realizovali zadatke zbog kojih i postoje. Izmeštanje remont- nih kapaciteta, pored spasavanja od uništenja ili oštećenja, može da se vrši i radi njihovog približavanja sredstvima koja treba održavati.

Dosadašnja iskustva govore da se ovom problemu nije suštinski poklanjalo dovoljno pažnje. Ne postoji adekvatno zakonsko utemeljenje u ovoj oblasti, nisu definisane nadležnosti i odnosi između vojno-teritorijalnih i drugih državnih organa, a nije ni ozakonjen postupak i obaveze vojnih i drugih organa koji koriste $i$ pružaju usluge, vezano za ovu delatnost.

Sve to nameće preku potrebu da se problemu posveti posebna pažnja. U vezi s tim potrebno je doneti potrebnu regulativu kojom bi se blagovremeno rešile sve dileme u procesu izmeštanja remontnih 
kapaciteta. Neizbežno se nameće i potreba za stalnim pripremama za realizaciju ovog zadatka.

Da bi se ovaj složeni zadatak realizovao potpuno i blagovremeno, potrebno je odrediti uslove pod kojima se proces odvija. Pored gotovosti sistema da ispuni funkciju cilja, potrebno je zadovoljiti i faktor rentabilnosti poslovanja.

Razlozi zbog kojih se vrši izmeštanje remontnih kapaciteta mogu biti:

- neposredna ratna opasnost - obično se izmeštanje kapaciteta planira mnogo ranije nego što dejstva otpočnu;

- ratna dejstva;

- elementarne nepogode, kao što su poplave, zemljotresi, požari i dr. Poznato je da su se remontni kapaciteti izmeštali posle velikih poplava;

- predislokacija - izmeštanje remontnih kapaciteta iz bivših republika SFRJ povlačenjem Vojske;

- približavanje sredstvima koja treba održavati - delimično izmeštanje i sa ograničenim ciljem).

Uslovi pod kojima će se izmeštanje odvijati mogu biti:

- danju ili noću;

- pod stalnom pretnjom dejstva iz vazdušnog prostora ili u vreme drugih priprema za realizaciju ratnih dejstava;

- pod otežanim klimatskim uslovima;

- uz dejstvo ili pretnju diverzantskih ili terorističkih grupa;

- sa ili bez adekvatne radne snage, sredstava za integralni transport i transportnih sredstava za prevoz;

- aktivnost može otpočeti sa ili bez plana, na brzinu, pre, u toku ili posle izvršene mobilizacije;

- pre ili u toku izvođenja borbenih dejstava.
Krajnji rok za realizaciju izmeštanja kapaciteta može da se posmatra kao vreme za izmeštanje radi spasavanja ljudi i sredstava od uništenja, ili kao početak funkcionisanja sistema za održavanje na novoj lokaciji. Težnja da se SOd odvija u svim uslovima podrazumeva da se izmeštanjem kapaciteta ne naruši princip neprekidnosti SOd.

Određivanje lokacija za razvoj jedinica za tehničko održavanje zahteva poseban pristup, prvenstveno sa aspekta uspešnosti sistema za održavanje. Koncept uspešnosti SOd-a može da se sagleda kroz ukupnu uspešnost SOd-a koja predstavlja funkciju organizacione, tehnološke i ekonomske komponente.

Struktura organizacionih celina za remont može biti: radno mesto, radna grupa, pokretna radionica, odeljenje, pogon, sektor, biro, zavod (fabrika).

Sadržaj organizacione celine mora definisati: broj organizacionih jedinica, strukturu organizacionih jedinica (remontnih celina) po radnim mestima, raspored remontnih celina u prostoru, ovlašćenja za izvršenje pojedinih zadataka preneta na organizacionu jedinicu, pripadnost remontnih celina karakterističnim nivoima održavanja, pravila međusobnog komuniciranja.

Maskiranje i adaptacija prostora za siguran rad usled dejstva protivnika predstavlja osnovni razlog njegovog preuređenja ili dogradnje.

Adaptacija prostora organizuje se tako da zadovolji osnovne uslove sigurnog rada. Za izvođenje mnogih radova na održavanju raketa, elektronskih uređaja i sl. potreban je betonski antistatički pod, određena vlažnost vazduha i najčešće napon od $380 \mathrm{~V}$, ,S“ izvedba električnih in- 
stalacija, ostali izvori energije, sabijen vazduh, voda, i drugo.

Prostor se uređuje i za smeštaj ljudi, obuku, odmor, kupanje, ishranu i ostale potrebe.

Radna snaga za utovar i istovar mora posebno da se planira za ove aktivnosti.

Transportna sredstva za prevoz ljudi i opreme na nove lokacije, moraju biti takva da mogu da prevezu specijalne alatne mašine, niskonoseće prikolice, $i \mathrm{dr}$.

Pri razmatranju opreme i sredstava integralnog transporta treba voditi računa o tome koje sredstvo može da se upotrebi na kojoj lokaciji.

Manevar kapacitetima i rezervama izvodi se radi izbegavanja udara protivnika, objedinjavanja kapaciteta, optimizacije transporta, pretpočinjavanja i evakuacije iz ugroženog rejona.

Mere borbene sigurnosti, bezbednosti i zaštite treba da omoguće da svaka celina funkcioniše po načelima borbene upotrebe vojnih sastava.

Za izmeštanje remontnih kapaciteta potrebna su i određena novčana sredstva, a mora se razmotriti i uticaj radnji izmeštanja remontnih kapaciteta na neprekidnost sistema održavanja, uspostavljanje informacionih i materijalnih tokova za nesmetano funkcionisanje sistema u celini, pretpočinjavanje i uklapanje nižih nivoa održavanja u više nivoe, raspolaganje sredstvima, prioriteti u radu, kao i limitirajući faktori i druga pitanja.

Izmeštanje remontnih kapaciteta, $\mathrm{u}$ zavisnosti od ukazane potrebe, mogu vršiti vojne jedinice na taktičkom ili operativnom nivou, vojne ustanove na strategijskom nivou i civilna preduzeća od posebnog interesa za odbranu zemlje.

\section{Elementi sistema održavanja koje treba izmestiti}

Održavanje tehničkih sistema predstavlja organizovan skup normativnih i tehničko-tehnoloških akcija čiji je osnovni cilj očuvanje i obnavljanje radnih sposobnosti tehničkog sredstva. Sistem održavanja predstavlja kompleks akcija, funkcija, postupaka, elemenata, principa i pravila u procesu održavanja. Održavanje predstavlja uslužnu delatnost koja je u vojnoj sredini koncipirana kao podsistem integralne logističke podrške.

Da bi SOd stalno funkcionisao na zadovoljavajući način, potrebno je u svim okolnostima sačuvati osnovne elemente sistema koji se planski izmeštaju na nove lokacije, kada postojeće, iz bilo kojih razloga, više ne odgovaraju nameni. Poteškoće u analizi elemenata sistema mogu predstavljati i činjenice koje ukazuju na to da je teško izraziti vrednost pojedinih elemenata, što otežava postavku bilo kog modela.

Elementi sistema za održavanje prikazani su na slici.

Kadar za održavanje (Od) propisan je formacijama vojnih jedinica-ustanova, a određen je kriterijumom za određivanje ličnog i materijalnog sastava tehničkih jedinica.

Kriterijum organizacijsko-formacijske strukture ličnog i materijalnog sastava jedinica za tehničko održavanje i snabdevanje TMS u ratu i miru (Tehnička uprava, 1997) propisuje broj ljudi po specijalnostima u različitim jedinicama za održavanje. Propisano je 79 različitih proizvodnih zanimanja po ovom kriterijumu.

Alat $i$ radionička oprema za održavanje predstavljaju skup svih standardnih 


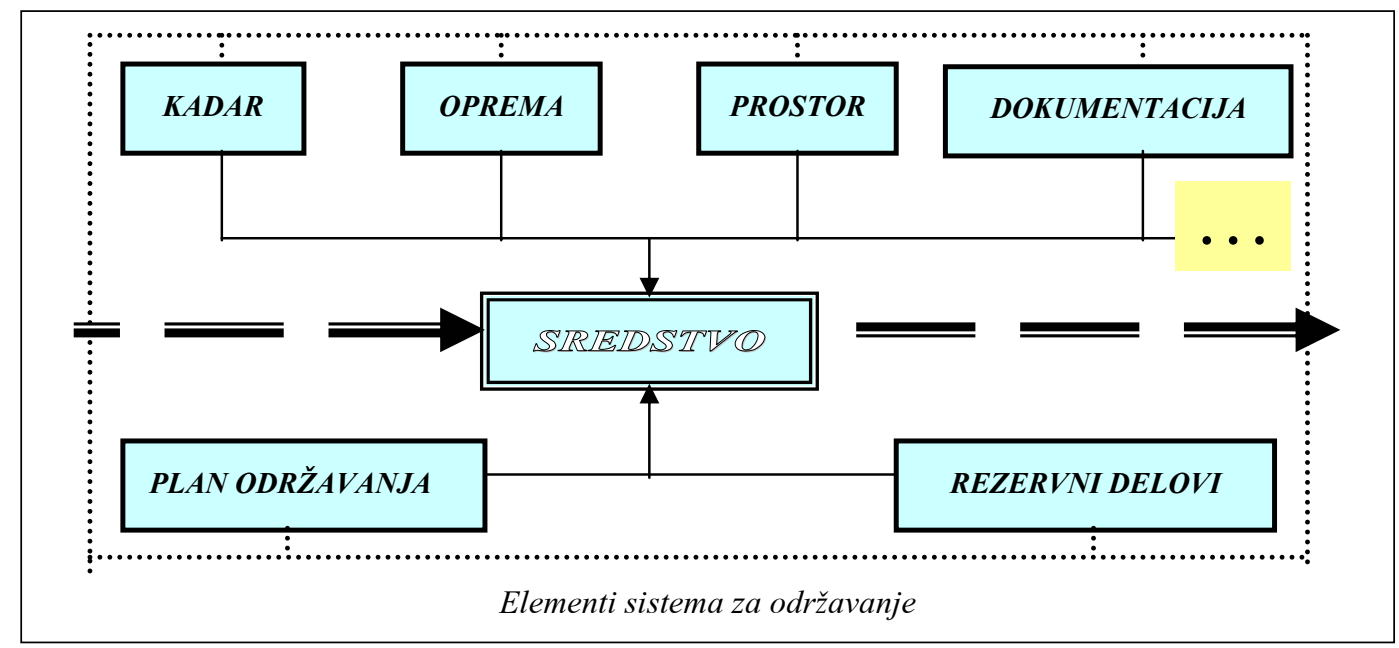

i namenski proizvedenih alata, pribora, pomoćnih uređaja, mernih i dijagnostičkih sredstava, neophodnih za kontrolu ispravnosti, detaljnu dijagnostiku i otklanjanje neispravnosti na tehničkim sredstvima. Alati se razvrstavaju kao:

- individualni kompleti i rezervni alati i pribori (IK i RAP) deo su opreme svih sredstava, bez obzira na njihovu složenost. To je, ujedno, i prvi nivo ešeloniranja alata i rezervnih delova. Sastav IK i RAP, materijal za izradu, oblik, dimenzije, kvalitet, zaštitu i smeštaj na konkretnom sredstvu, vrsta i količina r/d određuju se još u fazi razvoja konkretnog sredstva. RAP može biti i grupni, ako se određuje za grupu sredstava. Izmeštanje IK i RAP obavlja se uz konkretno sredstvo uz koje se on i nalazi;

- kompleti opšteg alata (KOA) za pojedine specijalnosti definišu se posebno za svaku specijalnost (zanimanje). Svaki komplet sačinjen je iz asortimana standardnih alata, na osnovu tehnološkog procesa i obima radova koje mehaničar određene specijalnosti može obaviti standardnim alatom. Alat i pribor iz ovih kompleta smešten je u standardizovanu ambalažu, limene sanduke dimenzija $220 \times 200 \times 500 \mathrm{~mm}$, ili u specijalne torbice, za mehaničare veze i elektronike i neka druga zanimanja. Materijal za izradu, oblik, dimenzije, kvalitet i zaštita određeni su odgovarajućim standardima. Princip dodele KOA je jedan mehaničar - jedan alat. Masa jednog kompleta, po pravilu, ne sme biti veća od $25 \mathrm{~kg}$. Svaki mehaničar za vreme rada i premeštanja nosi sa sobom svoj komplet opšteg alata;

- kompleti specijalnog alata i pribora (KSA) definišu se u toku razvoja svakog sredstva. Za obavljanje određenih tehničkih operacija iz okvira tehničkog održavanja, srednjeg i generalnog remonta, koje se ne mogu obaviti sa KOA, standardnim alatima i radioničkom opremom kontrolno-mernih, ispitnih i remontnih stanica, obezbeđuje se specijalni alat i pribor. KSA mogu biti razvijeni za svako sredstvo ili grupu sredstava. Po pravilu, definišu se za tehničko održavanje, srednji i generalni remont. Komplet za viši nivo sadrži elemente za niži nivo održavanja. KSA se isporučuje u odgo- 
varajućim sanducima čija bruto težina ne prelazi $75 \mathrm{~kg}$, dimenzija $900 \times 500 \times 300$ $600 \mathrm{~mm}$. Alat se nalazi u jednom ili više sanduka koji su prilagođeni paletizovanom transportu. KSA se dodeljuju jedinicama koje u svom sastavu imaju sredstva za koja su alati proizvedeni i mehaničare koji ta sredstva mogu da održavaju;

- pokretne tehničke radionice, kontrolno-merne, ispitne i remontne stanice koriste jedinice i ustanove za TOd i SR u terenskim uslovima. Kompleti mašina, uređaja, alata instrumenata i druge opreme iz pokretnih radionica, uz primenu kompleta opštih i specijalnih alata, treba da omoguće izvršenje svih radova iz domena TOd i SR koji su propisani za sve grupe sredstava. Pokretne radionice dodeljuju se po kriterijumu na svim nivoima koji imaju jedinice za održavanje. Prema kriterijumu propisana je 31 vrsta pokretnih radionica, a posebno su nabavljene ili proizvedene ispitne i specijalističke pokretne stanice;

- automobilske dizalice razvrstavaju se $\mathrm{u}$ grupe nosivosti do $10 \mathrm{t}$ i do $30 \mathrm{t}$;

- tenkovi za izvlačenje;

- kompleti za punjenje akumulatora sleduju svim jedinicama za održavanje PS. $\mathrm{U}$ praksi se posebno istakla pokretna $\mathrm{AkSt}$;

- kompleti za osvetljenje sleduju po vrstama i rangu komandama jedinica ili ustanova;

- stacionarna oprema (radni stolovi, zaštitna, radna i pomoćna oprema) i druga radionička oprema definisana je i nabavljena prema vrsti i nameni pogona i potrebama za adaptaciju radioničkog prostora, radi veće efikasnosti u radu. Raspoređena je po pogonima i, osim uslova koje nameće zaštita na radu, podleže opštoj tržišnoj standardizaciji.
Najčešće vrste opreme u vojnim radionicama, po pogonima, jesu:

- pogon za naoružanje - presa hidraulična, čistač cevi, kompresor, oprema za konzervaciju naoružanja i dr.;

- pogon za mototehniku - mašina za montažu i demontažu pneumatika, mašina za balansiranje točkova, platforma-dizalica, kanalska dizalica, platforma za izgradnju menjača, obične i specijalne dizalice, probni sto za elektropokretače, alternatore i generatore, probni sto za pumpe visokog pritiska, i dr;

- pogon mašinske obrade i opštih radova - univerzalni strug (veći i manji), stubna bušilica, stubna brusilica, mašina za ravnanje glave bloka motora, glodalica, mašina za ravno sečenje metala, presa hidraulična, dizalica radionička stubna, mašina za sečenje lima, mašina za profilisanje lima, mašina tapetarska, aparat $\mathrm{i}$ oprema za elektrolučno zavarivanje, aparat i oprema za autogeno zavarivanje, vaga za merenje, i dr.;

- pogon za belu tehniku i PP opremu - uređaj za unutrašnje čišćenje boca, uređaj za kontrolu ventila, kompresor, uređaj za hidraulično ispitivanje rezervoara pod pritiskom, uređaj za pretakanje ugljen-dioksida, vaga, uređaj za punjenje PP aparata halonom, uređaj za punjenje prahom, stona bušilica, i dr.;

Ukupna zapremina navedene opreme, koja se nalazi u jednoj četi remontne podrške, iznosi oko $200 \mathrm{~m}^{3}$, a masa oko 50 t. Karakteristike navedene opreme zahtevaju pažljivo rukovanje i prethodnu adaptaciju za transport i utovar viljuškarima ili dizalicama.

Prilagođenost konstrukcije za integralni transport i laku demontažu i ras- 
klapanje postoji samo na manjem broju mašina ili uređaja. Oprema nije prilagođena ni za vezivanje sajli za podizanje. Često se nalazi u prostorijama u koje ne mogu da uđu viljuškari, pa je mašine i uređaje posle demontaže potrebno prethodno izvući iz prostorija, a zatim utovarati. To zahteva delimično prilagođavanje podloge, korišćenje improvizovanih sredstava za pomeranje, a u nekim slučajevima i rušenje pomoćnih radioničkih zidova.

Prostor iz kojeg se izmeštaju kapaciteti mora biti podešen za rad sredstava za integralni transport, sa visokim plafonima, ravnom i jakom podlogom, sa kružnim tokom saobraćaja, i dr.

Tehnička i druga dokumentacija, informatička oprema, i ostala sredstva za normalno obavljanje remonta predstavljaju veoma važan deo bez kojeg informacioni tokovi upravljačke strukture SOd ne bi mogli da funkcionišu. To su:

- liste (listinzi) dugovanja PS, alata, r/d, i dr.;

- tehnička uputstva za održavanje, TS-1 i TS-2, tehnička remontna dokumentacija - TRD, fabrička uputstva za održavanje;

- imenici rezervnih delova, TS-3, fabrički katalozi;

- hardverska oprema, softverski paketi.

Planovi za održavanje moraju da se izrađuju i na novoj lokaciji, prilagođeni novonastaloj situaciji.

Rezervni delovi, potrošni i repro materijal. Svaka jedinica u kojoj se vrši održavanje u svom sastavu ima i jedinicu (magacin) rezervnih delova. Iskustva pokazuju da izmeštanje magacina traje najduže sa najviše izraženih problema. Svi podaci ukazuju na činjenicu da su magacini pretrpani nepotrebnim rezervnim delovima koji nisu paletizovani i pripremljeni za izmeštanje. Podaci nameću preku potrebu da se zalihe svedu na potrebnu meru i da se projektuje adekvatan sistem upravljanja zalihama $\mathrm{r} / \mathrm{d}$.

\section{Uslovi za razvoj jedinica za tehničko održavanje} Opšti uslovi za razvoj jedinica za
održavanje

U Vojsci SCG postoji više jedinica za održavanje - od nivoa LR, SR, do GR. Da bi se definisali kriterijumi za izbor lokacija i objekata, potrebno je poznavati njihovu organizacijsko-formacijsku strukturu, plan upotrebe jedinice u kojoj se jedinica za održavanje nalazi, razvoj jedinica koje sistem za održavanje treba da opsluži, kao i način funkcionisanja upravljačke strukture u novonastaloj situaciji.

Iskustva pokazuju da je najbolje rešenje da se jedinice razviju u stacionarnim objektima, postojeće privredne i druge infrastrukture, kombinovano ili, u krajnjem slučaju, na otvorenom prostoru uz korišćenje formacijskih sredstava za život i rad. Dobro je da se izmeštanje obavlja u dve faze - I faza, u kojoj se izmeštaju vozila i kompleti alata i II faza, u kojoj se izmeštaju r/d i radionička oprema.

Opšti zaključak je da su pokretne radionice nezamenljive u postojećem sistemu, a da su neophodni: sredstva veze, informatička podrška, način prenošenja informacija i komandi.

Moguće je postaviti opšte kriterijume koji moraju da zadovolje sve lokacije na koje se izmeštaju remontni kapaciteti: 
- rastresit raspored i nesmetan manevar rezervama, transportnim sredstvima i sredstvima integralnog transporta,

- povoljni uslovi za adekvatno maskiranje ljudi i izmeštenih stvari,

- optimalni uslovi za formiranje tehnoloških celina za rad,

- adekvatni uslovi za odmor, ishranu, obuku,

- pogodnost sprovođenja mera ZOP, ZNR, ZŽS, zdravstvene zaštite,

- da nema unosnih ciljeva u blizini,

- dobri prilazni putevi, kao i potrebni kvalitetni putevi unutar odabrane lokacije.

\section{Kriterijumi za izbor lokacija za izmeštanje remontnih kapaciteta}

Osnovni kriterijumi za izbor lokacija za izmeštanje remontnih kapaciteta su taktički i organizaciono-tehnološki.

Taktički kriterijumi odnose se na upotrebu jedinice za održavanje, njenu manevarsku sposobnost, položaj u odnosu na druge elemente borbenog rasporeda snaga koje se podržavaju u sistemu održavanja, kao i snaga protivnika. U ove kriterijume spada i potrebna zona sigurnosti za bezbedan i nesmetan rad, pri čemu se teži da uticaj neprijateljeve vatre na jedinicu za Od bude najmanji, a uslovi za život i rad najpovoljniji. Pri izboru lokacije treba imati u vidu: operativnost $\mathrm{u}$ radu, što manji utrošak sredstava i resursa, što manje gubitke i što veću gotovost sredstava koja se održavaju. Umesto izvlačenja i evakuacije sredstava treba im približiti resurse za održavanje.

Taktički kriterijumi mogu da se razlože u sledeće grupe [2]:

- vojnogeografske karakteristike zemljišta - udaljenost od naseljenog mesta, udaljenost od potencijalne desantne prostorije, udaljenost od unosnog cilja;

- položaj lokacije u odnosu na druge elemente borbenog rasporeda - udaljenost od komandnog mesta, udaljenost od skladišta $\mathrm{r} / \mathrm{d}$, udaljenost od medicinskog centra;

- karakteristike rejona rasporeda površina potencijalnog mesta, srednja udaljenost prostora za rad i smeštaj ljudstva, udaljenost između sekcija, broj i raspored zaklona za ljude i vozila, broj i raspored stražarskih mesta;

- karakteristike komunikacija - broj mogućih uređaja za održavanje veze, najkraća dužina puta do linije fronta, dužina puta do glavnih snaga, broj komunikacija za korišćenje, ukupna dužina puteva, udaljenost železničke stanice, broj mostova, nadvožnjaka, prevoja.

Organizaciono-tehnološki kriterijumi odnose se na potrebu formiranja određene tehnološke celine, kako bi sistem za održavanje mogao zadovoljiti osnovnu funkciju cilja zbog koje je i formiran, a to je održavanje sredstava ratne tehnike $\mathrm{i}$ drugih sredstava. Ovi kriterijumi zahtevaju manja rastojanja između remontnih celina, kako bi bilo što manje gubitaka $u$ radu, a što se kosi sa taktičkim kriterijumima koji zahtevaju što rastresitiji raspored radi bolje zaštite. Tehnološki proces odvija se u formiranim sekcijama ili na mestima oštećenja. Pokretne ekipe upućuju se na mesta oštećenja - nastanka neispravnosti. Osnovni princip rada je agregatni, a po stvaranju uslova vrši se i regeneracija delova, sklopova $i$ agregata.

Organizaciono-tehnološki kriterijumi mogu da se razlože u sledeće grupe:

- prostor - korisna radionička površina u prostorijama do $4 \mathrm{~m}$ visine, od 4 
do $8 \mathrm{~m}$ visine, nosivost podloge od 7 do $25 \mathrm{t}$, od 25 do $45 \mathrm{t}$, broj i površina prostorija sa izrazito povoljnim uslovima za obavljanje specijalnih radova, površina zatvorenog skladišta, srednja udaljenost od SOT, vreme potrebno za adaptaciju prostora za rad;

- oprema - broj i mogućnost korišćenja sredstava za integralni transport pri radu i manipulaciji sa rezervnim delovima i sklopovima, broj kanala, broj kranova i kanalskih dizalica, broj i vrsta instaliranih mašina i uređaja, mogućnost opterećenja električne i druge instalacije;

- uslovi radne sredine - ventilacija, odvojenost prostorija za boce pod pritiskom, mogućnost odvoda i odlaganja opasnih i otpadnih materija, osvetljenje, temperatura, vlažnost vazduha, zaštita od jonizujućih zračenja, ZOP, smeštaj ljudi, mogućnost za normalan odmor, ishrana, higijenski uslovi, zaštita od buke i vibracija;

\section{Zaključak}

Proces izmeštanja remontnih kapaciteta, u dosadašnjoj praksi, više se odvijao stihijski nego planski. Trebalo bi da bude zasnovan na merilima utemeljenim propisima koji definišu strategijske radnje u pripremi i izvođenju borbenih dejstava.

Praksa pokazuje da je infrastruktura za izbor lokacija povoljna, ali da ne po- stoji adekvatna regulativa $u$ rešavanju ovog problema.

Radi unapređenja postojećeg stanja potrebno je, pre svega, doneti adekvatne propise iz ove oblasti, formirati bazu podataka koja bi bila dostupna licima koja vrše planiranje, izvršiti obuku ljudstva za pravilan izbor lokacija za izmeštanje remontnih kapaciteta, kao i propisati redosled radnji pri planiranju i realizaciji plana. Pored toga, važno je da se propiše i sadržaj plana izmeštanja, kao i nadležnosti pojedinih nivoa u donošenju odluka pri realizaciji plana.

Izmeštanje je potrebno planirati $u$ više varijanti, a elemente sistema pripremati u miru, kako bi izmeštanje bilo u potpunosti realizovano prema unapred izrađenim planovima.

Literatura:

[1] Avrić, D.: Upotreba bataljona remontne podrške, GŠŠ, 1997.

[2] Andrejić, M. i dr.: Definisanje kriterijuma za izbor rejona razmeštaja tehničkih jedinica za održavanje, VTG 1/96.

[3] Stanojević, P.: Uticaj tehničkih faktora na organizacionu strukturu sistema održavanja, Doktorska disertacija, 1997.

[4] Grupa autora, Iskustva iz rada bataljona remontne podrške, 1999.

[5] Uputstvo za raseljavanje, disperziju i zaštitu pokretnih stvari (privremeno)-nacrt, GŠ, SL, OUL, 2003.

[6] Vojne softverske aplikacije nad digitalnom kartom, radni mat., 2004.

[7] Cakić, A.: Logistički kontroling u savremenim logističkim sistemima, VTG 1/2003.

[8] Nikolić, M. i dr.: Kvantifikacija osnovnih kriterijuma logistike, VTG 1/2004.

[9] Jovanović, D.: Mogućnost poboljšanja tehničkog održavanja u realnom sistemu, 1998.

[10] Stanojević, P. i dr.: Strategije održavanja tehničkih sistema, VTG 6/2003.

[11] Vujanović, N.: Teorija pouzdanosti tehničkih sistema, VINC 1987.

[12] Grupa autora, Iskustva iz rada bataljona remontne podrške u toku rata 1999. godine, 1999. 